\title{
The space for social media in structured online learning
}

\author{
Gilly Salmon ${ }^{\mathrm{a}}$, Bella Ross ${ }^{\mathrm{b} *}$, Ekaterina Pechenkina ${ }^{\mathrm{c}}$ and Anne-Marie Chase ${ }^{\mathrm{d}}$ \\ ${ }^{a}$ Office of the Pro Vice-Chancellor (Education Innovation), The University of Western Australia, \\ Crawley, WA, Australia; ${ }^{b}$ Student Academic Support Unit, Monash University, Monash, Caulfield, \\ VIC, Australia; ${ }^{c}$ Learning Transformations Unit, Swinburne University of Technology, Hawthorn, \\ VIC, Australia; ${ }^{d}$ Australian Council for Educational Research, Camberwell, VIC, Australia
}

(Received 12 May 2015; final version received 23 November 2015)

\begin{abstract}
In this paper, we explore the benefits of using social media in an online educational setting, with a particular focus on the use of Facebook and Twitter by participants in a Massive Open Online Course (MOOC) developed to enable educators to learn about the Carpe Diem learning design process. We define social media as digital social tools and environments located outside of the provision of a formal university-provided Learning Management System. We use data collected via interviews and surveys with the MOOC participants as well as social media postings made by the participants throughout the MOOC to offer insights into how participants' usage and perception of social media in their online learning experiences differed and why. We identified that, although some participants benefitted from social media by crediting it, for example, with networking and knowledge-sharing opportunities, others objected or refused to engage with social media, perceiving it as a waste of their time. We make recommendations for the usage of social media for educational purposes within MOOCs and formal digital learning environments.
\end{abstract}

Keywords: MOOCs; social media; learning design; online identity; Facebook; Twitter

\section{Introduction: social media in learning}

In this paper, we explore the role played by social media in a Massive Open Online Course (MOOC) offered by an Australian university. Social media sites are increasingly being used for educational purposes and a range of benefits and drawbacks have been documented in the research. We examine how the usage of social media in the MOOC enhanced participants' overall learning experience and how it led to increased networking and knowledge sharing with peers. We also report on the negatives of social media usage as perceived by the participants. These lessons may inform future design choices of the inclusion of social media in MOOCs and other structured digital learning.

Social media in higher education has been found to enhance learning outcomes and academic achievement (Junco, Heiberger, and Loken 2010; Özmen and Atici 2014), and to contribute to knowledge construction (DeWitt et al. 2014; Kassens-Noor 2012). Social media can assist students to share administrative information with peers, such as meeting times and locations, and assessment requirements (Bosch 2009; Selwyn 2009), and also to network and promote peer feedback (Davies et al. 2010).

*Corresponding author. Email: bella.ross@monash.edu

Responsible Editor: Carlo Perrotta, School of Education, University of Leeds, United Kingdom.

Research in Learning Technology 2015. (C) 2015 G. Salmon et al. Research in Learning Technology is the journal of the Association for Learning Technology (ALT), a UK-based professional and scholarly society and membership organisation. ALT is registered charity number 1063519 . http://www.alt.ac.uk/. This is an Open Access article distributed under the terms of the Creative Commons Attribution 4.0 International License (http://creativecommons.org/licenses/by/4.0/), allowing third parties to copy and redistribute the material in any medium or format and to remix, transform, and build upon the material for any purpose, even commercially, provided the original work is properly cited and states its license. 


\section{G. Salmon et al.}

When deployed for learning, social media can facilitate the development of online communities, allowing for collaborative and participatory engagement by placing emphasis on collective knowledge and social interaction (Maloney 2007; Wodzicki, Schwämmlein, and Moskaliuk 2012). Social media can help strengthen the social relationships among students, heighten students' self-esteem, and boost their learning performance (Llorens and Capdeferro 2011; Yu et al. 2010). Students may be more willing to voice their opinions or disagreement with peers in an online discussion rather than in a face-to-face setting (Ellison, Steinfield, and Lampe 2007; Kim 2008; Oblinger and Oblinger 2005; Sullivan 2002; Thompson and $\mathrm{Ku} 2005$ ). Further, online social interaction allows shy students to contribute and be 'heard' by the group (Davies et al. 2010) and thus may provide benefits to those with lower self-esteem (Ellison, Steinfield, and Lampe 2007).

Although university-utilised learning management systems (LMSs) and social media platforms both enable file sharing, collaboration and discussion (Gray, Annabell, and Kennedy 2010), social media platforms tend to be more popular with students for peer-to-peer interactions (Davies et al. 2010; Veletsianos and Navarrete 2012) due to their familiarity and flexibility. Peer learning communities (off and online) have been identified as a way to foster the development of higher order thinking skills and increase student and academic engagement, interaction, retention, and satisfaction (Brownell and Swaner 2010; Dodge and Kendall 2004; Yuan and Kim 2014). In MOOCs, where engagement and motivation tend to be low (de Freitas, Morgan, and Gibson 2015; Yang et al. 2013), social media may be beneficial in fostering online learning communities, which, in the context of a MOOC, are necessarily located online, enabled by an LMS (also referred to as Virtual Learning Environment) or social networking site.

Online learning communities have been found to engage students in collaborative learning and reflective practice (Oliver et al. 2007). The research into online learning communities should, however, be viewed with caution, as the term is often used without clear or common definitions or rigorous theoretical underpinnings (Henderson 2015). The term is often used uncritically to describe collaboration with overly positive overtones of social support. Some researchers offer definitions for the online learning community (Lai 2015): The participants have a shared goal, support one another, produce material collaboratively, show a sense of belonging to the community, and are interested in the welfare of its members. Excellent as these qualities are, current research indicates that they are neither aspired to nor achieved by the design of online communities. Consequently, this paper aims to examine how participants leveraged social media to network with others to exchange information and knowledge.

Many of the positives of deploying social media in digital education, outlined above, have also been challenged, with some studies highlighting that there is no adequate evidence that social networks provide an arena for all students to develop critical and independent thinking skills (Henderson, Selwyn, and Aston 2015; Ziegler 2007). Other studies show that students feel that social media reduces student collaboration because students work separately on different parts of a project, which minimises opportunities for collaborative learning (Hrastinski and Aghaee 2012). Students also report that using social media in learning may lead to misunderstandings, less knowledge sharing, and less creative thinking (Hrastinski and Aghaee 2012). Furthermore, the quality and accuracy of the information shared in collaborative social media spaces varies greatly (Laird 2014). 
Some students report seeing the use of social media such as Facebook as time wasting or a form of procrastination (Davies et al. 2010). Studies such as Madge et al. (2009) argue that students are not keen to use Facebook for formal discussions relating to teaching and learning, or to liaise with instructors. Students may feel that using social media in education distorts the boundaries between their online social and educational worlds, between social and informal and formal spaces, and between public and private spaces (Land and Bayne 2008). Both students and academics may feel that social media for educational purposes interferes with their private lives, which raises concerns about representing identities in the online environment (Aghili et al. 2014; Tess 2013; Veletsianos and Navarrete 2012).

Particular to MOOCs, participants may feel overwhelmed and as just one 'faceless student' out of many (Knox 2014). Participation in MOOCs can provoke anxiety in a learner about their presence and orientation in relation to large-scale activity (Kop, Fournier, and Mak 2011), and can cause a sense of loss of identity and individuality (Knox 2014). Participants have described MOOCs as depersonalised and lacking a meaningful student-teacher relationship (Levinson 2013). Students in MOOCs may feel anxious that they are missing out on important information and discussions; the many online opportunities and 'spaces' of the course can cause students to feel confused and overwhelmed (Knox 2014).

Despite a large body of scholarly work on MOOCs and digital education, with broader and quickly growing scholarship focusing on the educational use of social media, there is still a scarcity of studies specifically looking into the usage of social media in MOOCs. This paper seeks to contribute to this gap of knowledge and offer some insights into how social media can be successfully deployed in a MOOC. 'How and to what extent does social media enhance or complement participants' overall learning processes and outcomes?' is the key question that drives us to be particularly interested in investigating two outcomes. First, why did the CD MOOC participants chose to spend time in social media platforms in addition to the structured LMS provided? Second, what was the impact, if any, on their learning, experience and engagement?

\section{The context for the study: the Carpe Diem MOOC}

The Carpe Diem Massive Open Online Course (CD MOOC) was designed and delivered by Swinburne University of Technology (Australia) in 2014. The MOOC was designed to attract educators from all sectors interested in designing their own courses. The goal of the CD MOOC was to equip participants with the knowledge and skills to develop their own online and blended teaching materials and processes through a practical design approach.

Just over 1,000 participants accessed the CD MOOC. They were mainly in the 46-year-plus age bracket; employed in the education sector; and the majority were female (Salmon et al. 2015). Participants were allocated into small online groups, and tasked with designing and planning their own courses with a focus on student-centred learning, and using innovative learning technologies. There was a high level of engagement and completion.

The pedagogy of the Carpe Diem process is a socially mediated constructivist approach that uses rapid project development and creative problem-solving techniques for quick and collaborative design (Salmon 2013, 2015; Salmon and Wright 2014; Salmon et al. 2015). The CD MOOC aimed to provide participants with an experience 


\section{G. Salmon et al.}

of working through the six stages of the Carpe Diem learning design process: Write a Blueprint, Design a Storyboard, Build a Prototype, Check Reality, Review and Adjust, and Build an Action Plan. The Carpe Diem process, which usually takes place over 2 days with co-located participants, was adjusted to suit an asynchronous digital open course.

Hosted on the free CourseSites (provided by Blackboard ${ }^{\mathrm{TM}}$ ) LMS, the CD MOOC process was defined by extensive group work and peer review. At the beginning of the CD MOOC, participants were randomly enrolled into groups of approximately 30 participants, and were guided and supported by a MOOC moderator over the 6-week period.

In addition to the structured LMS, more informal social media elements were offered. The CD MOOC designers selected Facebook and Twitter as social media platforms for participants to use, based on the studies that social media contributes to collaborative learning experiences (Balakrishnan 2013; Blaschke 2014; Llorens and Capdeferro 2011; Maloney 2007; Yu et al. 2010).

The Facebook group and the Twitter hashtag (\#CDMOOC) were created in February 2014 to coincide with the beginning of the CD MOOC. Both social media outlets were open to all CD MOOC participants. The Facebook group was a closed group that required participants to request to be added by the Carpe Diem Facebook page moderators.

Both the CD MOOC Facebook group and the Twitter hashtag \#CDMOOC were extensively advertised to participants through general announcements on the CD MOOC's CourseSites page, tweets via the CD MOOC's official Twitter account and through the text-based online and printed literature advertising the MOOC. Twitter was also linked directly to the CD MOOC Facebook group by including the Twitter hashtag in Facebook posts.

On the Facebook group, moderators guided participants to ask questions about the CD MOOC, seek practical help, communicate and discuss issues around work tasks, and share links to online group work and resources. Twitter was used by both the CD MOOC team and participants to share practical information and resources, while also encouraging participants to share their thoughts and experiences.

\section{Methodology}

The data for this study were collected via an anonymous online survey, interviews with a randomly selected group of survey respondents and Twitter and Facebook postings by the CD MOOC participants throughout the duration of the MOOC. These methods were selected as they are mutually enriching by allowing for an in-depth investigation of topics of inquiry initially revealed by the survey responses. The survey consisted of six Likert-scale questions, two write-in general feedback questions and six demographic questions. The survey questions covered aspects such as the students' evaluation of the usefulness of the CD MOOC and their engagement with its various elements, including its length, structure, the use of videos, resources and digital badges. The write-in questions directed the respondents to identify the most useful aspects of the CD MOOC and explain why the features were useful. The survey was sent out to the entire CD MOOC participant cohort and was completed by 155 respondents.

No survey questions were specifically designed to gauge students' engagement with social media elements (Facebook and Twitter), however, the theme of social media naturally emerged from the write-in responses data. To further explore how social 
media in the CD MOOC influenced students' educational experiences, a question about social media was included in the interview schedule, with the ultimate goal of correlating interviewees' responses on the usage of social media in the CD MOOC with the survey findings.

After the survey completion, 29 of the survey respondents consented to be interviewed. Semi-structured telephone interviews were conducted, transcribed and de-identified. In regards to the interview respondents' use and experiences of social media in the CD MOOC, we asked whether interviewees felt motivated to engage in informal interaction with their peers in online spaces outside of the CD MOOC structured environment, and whether or not, or to what extent, they felt social media helped their learning. Interviewees were also asked whether they interacted with other CD MOOC participants on Facebook or Twitter, and whether they thought that social media improved their learning outcomes.

We utilised the analytical software Dedoose to conduct a thematic analysis of the interview transcripts, open-ended survey responses and social media postings, in which social media was identified as one of the frequently discussed topics. The analysis of the data collected from the three sources was guided by the mixed-methods approach (Bazeley 2012), in which we triangulated the findings to facilitate the process of concept formation and identify frequently mentioned concepts and causal inferences (Strauss and Corbin 1998), though the latter was problematic considering the small size of the samples. Another level of triangulation was achieved by having data systematically (co)analysed and (co)checked by the authors. The processes of data triangulation produced high levels of inter-reliability through comparisons, moderation and thorough discussions of the data and any inconsistencies that arose between the authors. Throughout the reporting of findings, we treat the triangulated data as one body of knowledge. The three key themes which emerged from the body of data are discussed next.

\section{Findings}

\section{Participation in social media}

Having first emerged as a major theme from the survey's write-in responses data, social media then became one of the main topics of inquiry investigated via the interviews. The social media postings data revealed that Facebook was most frequently used by the CD MOOC participants, compared to the microblogging site Twitter. Participation in the Facebook group continued actively for around 3 months (up to May 2014) with some participants 'signing off' by displaying their certificate of completion. The Twitter hashtag attracted 664 tweets over a 9-month period. Initially, Twitter was used by participants to announce their intention to participate in the CD MOOC, and then during the MOOC to gather, provide and exchange resources and information.

Interview participants were specifically asked whether they used social media throughout the CD MOOC and if so, whether they used Facebook or Twitter, or both, and how they engaged with either platform. The usage data quantified on the basis of interview transcripts (Table 1) shows that approximately half of all interviewees used at least one of the social media platforms in the CD MOOC. The most used form of social media was Facebook (used by $31 \%$ ), a small minority (3\%) used Twitter only, while $14 \%$ of interviewees utilised both Facebook and Twitter. 
Table 1. Interview responses: Did CD MOOC participants use social media?

\begin{tabular}{lc}
\hline Did participants use social media during the & $\begin{array}{c}\text { Percentage }(\%) \text { of interview cohort } \\
(N=29)\end{array}$ \\
CD MOOC? & 41 \\
No & 14 \\
Yes, all - Twitter and Facebook & 31 \\
Yes - Facebook only & 3 \\
Yes - Twitter only & 10 \\
Question not asked & \\
\hline
\end{tabular}

Confusing the findings from the Tess's (2013) study, the interviews clarified that the different social media platforms were used for different purposes by the CD MOOC participants. The Facebook group was used for discussions, while Twitter was used for gathering and providing information.

\section{Emerging themes}

Analysis of the survey's write-in responses and the interview narratives helped us identify three key themes that emerged in relation to participants' use of and engagement with social media in the CD MOOC. The first theme revealed that the online collaboration through social media assisted participants by enhancing their learning. The second theme showcased that many participants enjoyed and benefitted from using social media to engage with a diverse range of people with whom to network and exchange knowledge. Finally, the third theme illuminated the reasons behind participants' objections or reluctance to use social media within their structured online learning experience.

\section{Theme 1: improving learning}

Approximately half (14) of the interviewed participants used the CD MOOC Facebook group during the duration of the MOOC, mainly with the intention of improving their learning outcomes. These participants reported various positive social aspects of their learning process enhanced by using Facebook, confirming other studies (Brownell and Swaner 2010; Dodge and Kendall 2004; Kassens-Noor 2012). Participants who used the CD MOOC Facebook group, but did not use Twitter, thought that social media was useful for posting and gathering information, and that Facebook improved their learning outcomes by facilitating discussion with peers and moderators. Facebook was also seen as an easy aid to increase learning and encourage discussions with peers as it facilitated the sharing of videos and images, and hence allowed participants to directly see others' work. Facebook also served as a spark for a discussion, which could then be built upon within the more structured MOOC environment. One participant noted:

For me, the most useful activities were designing and giving feedback on the e-tivity, an opportunity to use the templates provided. Aside from that, [the most useful aspects were] the enormous amount of discussion generated through various media both within and outside the course environment.

A number of interview participants stated that they were unable to use social media as much as they would have liked, as a result of either a lack of time or lack of interest 
among other CD MOOC group members in participating in the Facebook group. Despite their lack of engagement with Facebook, these participants perceived social media as being helpful to their collaborative learning efforts whether they engaged with either Facebook or Twitter. Another perceived benefit of participants engaging in social media was more knowledge sharing - it was suggested that the large amount of discussion generated on Facebook was one of the most useful aspects of the CD MOOC experience.

\section{Theme 2: networking}

Both survey and interview participants spoke of the benefits of networking with people from different backgrounds, locations and professional affiliations when using social media platforms to connect and further their learning outcomes in the CD MOOC. One participant stated:

I love the fact that ... you're networking with people all over the world and just such an incredibly empowering thing. A lot of my colleagues feel that because they work in ... a government education department they should only really talk to people ... in their own area and I just love that whole knowledge of being able to ... communicate with someone in Ireland and ... someone in Israel and it's very empowering I think. And it also made me feel good because they know lots of stuff, so I felt really confident and comfortable.

Another participant mirrored the sentiment above: 'collaborating with participants worldwide made it a great cultural experience, particularly in seeing how social media is taking on the world'. Another confirmation of this sentiment came from a tweet: '[Our] team are networking as well \#CDMOOC finding interesting connections from the online world!' Finally, as another participant stated:

Learning from peers and using learning platforms such as discussion boards, wiki, the CD MOOC and others enhanced this process and helped make this happen! I personally found this experience, although challenging at times, useful and interesting. It kept me engaged and motivated to explore and engage with others. I particularly enjoyed freely sharing knowledge on a wide and global scale!!

These responses, provided by both interview participants and survey respondents as well as interspersed throughout the Facebook and Twitter feeds, exemplify how strongly the CD MOOC participants felt that they were part of a larger online learning cohort with shared goals, and in a collaboration with peers on social media that aided their learning and in general enriched the CD MOOC experience.

\section{Theme 3: objections to using social media}

Despite the positive comments outlined in the previous section, a significant segment of the CD MOOC participants who took part in interviews (41\%) did not use any forms of social media as part of the CD MOOC experience. The main objections to using social media can be divided into three categories: a belief that social media might be a waste of time; the perception of social media platforms as confusing or intimidating; and concerns about blurring social and professional identities. These objections are discussed in the following sections. 


\section{G. Salmon et al.}

\section{Time to engage with social media}

Among reasons for not engaging with social media in the CD MOOC, a lack of time emerged with a systematic frequency: these participants believed that social media would 'take time away' from what could otherwise have been spent on the structured parts of the CD MOOC, a concern that is reflected in other studies (Davies et al. 2010). Within this group, some were negative towards social media in general, seeing it as a waste of time, both inside and outside of the CD MOOC. This sentiment among participants is exemplified by the interview excerpt below in which a participant did not engage with social media for lack of time; he thought that time spent on social media would detract from the time he could spend on coursework. It might be that more time is required if the platform is unfamiliar. It was important to many participants that they were comfortable using social media, however, and they avoided unfamiliar platforms.

I made a couple of tweets myself but they were just generally looking forward to doing a CD MOOC and everything. I didn't actually respond to anybody else's tweets on there but I did have a look every so often. But again that's another time issue. You know you're looking on the community and the Twitter and all of the social things and you end up tearing off your actual course work [emphasis added].

Meanwhile, a number of participants wanted to use the social media with which they were familiar and comfortable. Some of these participants were notably less enthusiastic about the use of CourseSites LMS of the CD MOOC, instead preferring to spend time on social media. This finding fits in with the literature emphasising that learners often prefer to use the social media to which they are already accustomed (Kaeomanee, Rias, and Perveen 2012; Veletsianos and Navarrete 2012). Such learners find social media easier to use, or more 'advanced' than the institutionally provided LMS (Davies et al. 2010).

A participant who did not interact with others via Facebook or Twitter attributed this indifference to time constraints and multiple other commitments, and 'preferred to do [use social media] because it would have given [the CD MOOC] a little more structure'. The same participant also stated that it would have been simpler to use Facebook, which was familiar, instead of CourseSites, which this person described as 'cumbersome'.

Participants generally reported being more comfortable using platforms that they were more accustomed to - typically Facebook. The participant cited below used Facebook to gain knowledge of the CD MOOC's coursework through online peer discussions, however, did not feel comfortable using Twitter:

I tried to get in touch with the course participants to get informed about the discussion around this course so I registered on Facebook and also Twitter. The use of Facebook is quite helpful but Twitter did not work because it was not the social media I am accustomed with.

This apparent trend of participants preferring to engage with the CD MOOC via social media rather than LMS can be explained by the existence of navigational issues with the CD MOOC's LMS, another common theme in both surveys and interviews. We conclude that a significant segment of participants did not see the value of social media in the CD MOOC, mostly because they were concerned about losing the time they had available to spend on coursework. 


\section{Confusion or intimidation}

Another objection by participants related to their lack of knowledge about social media platforms and their resulting confusion. A participant voiced strong opinions about the use of Facebook and Twitter for educational purposes: 'I absolutely disagree with that [Facebook and Twitter]. I hate Facebook, I don't think it's an appropriate forum. I dislike it'. She believed that in order to 'get as much bang for your buck in as short a time as possible', all information should be in one place, and information spread over several social media sites can get lost: 'You want to say it once, say it clearly and keep it all in one place and that way it's easy to get onto the points'.

Other participants held similar ideas - they expressed their confusion at the range of online communication channels available during the CD MOOC: '\#CDMOOC to tweet or FB? Don't feel I can do both. Plus wiki plus group discussion board. Collaboration galore!' This participant echoes this conflict between social media platforms:

While it is great to encourage using other forums [outside the CourseSites] to collaborate, it created more confusion as we did not know where to go to stay in touch. Encouraging a set place as a common thread would have been helpful at the start.

In practice, we noted that the $\mathrm{CD}$ MOOC groups had some difficulty reaching consensus about which platforms to use for their work because of the variety of opinions within the groups about which social media sites were appropriate. However, those participants in groups who used both Facebook and Twitter found the experience of using both platforms extremely helpful, though not without initial disagreements. For example:

We had a bit of a problem in our group in the beginning because instead of thinking about the process we had a couple of people who were arguing about whether social media was any good, so it kind of got a bit out of hand ..., 'No, we're not using Facebook because of this, this, this and this' but they weren't kind of thinking about what the process was of the actual Carpe Diem design methodology. Rather they were thinking of, 'Do I like social media or don't I?' So that kind of overtook that a little bit.

Such comments are not unusual in the literature on MOOCs. Students may feel that they are 'missing out' if they do not follow every thread or post on the connected social media platforms (Knox 2014). Other research (Henderson, Selwyn, and Aston 2015) tells us that students prefer having all of their course content and materials located in one place, such as the official LMS. Our study demonstrates, however, that those participants who made a decision to engage with the social media elements of the CD MOOC found the experience rewarding.

\section{Blurring of social and professional identities}

A third key objection of participants to engaging with the social media elements of the CD MOOC dealt with reluctance about what was perceived as a potential merging of professional and social identities. One of these participants, who felt uneasy interacting with other participants using social media, preferred to separate his networking and more formal learning approaches:

I did not use Twitter or Facebook. Those are social sites. For professional work, I prefer it to be on a professional platform ... I don't use Facebook and Twitter anymore.

This participant saw the CD MOOC as an adequate source of course information, stating that: 'the collaboration messages inside the tools on Blackboard are more 


\section{G. Salmon et al.}

than sufficient'. Comments like these demonstrate that some participants discounted social media as a valuable way to gain knowledge and engage with peers in an online community.

Another participant stated that using social media for the purposes of the CD MOOC felt too intimating to her: 'I don't do Twitter, Facebook ... I didn't want to get on Facebook with them ... [it] was a little too intimate'. The reluctance to blur social and professional identities is a common theme emerging from the literature on online learners and MOOC participants (Aghili et al. 2014; Jones et al. 2010; Land and Bayne 2008; Veletsianos and Navarrete 2012). Based on their findings, Jones et al. (2010) recommend that learning design address individual student preferences to either combine or separate their online identities.

\section{Summary of objections}

Those who reported being uncomfortable using social media cited three main reasons for not wanting to engage in social media for their formal learning. First, they did not believe that there was any learning value in using social media sites, and that it was a waste of their time. Second, they found the social media landscape too confusing and intimidating. Third, they did not want to blur what they perceived as the socialprofessional divide.

\section{Conclusions}

The experience of delivering the CD MOOC allowed us to study how participants engaged with the social media within the MOOC along with the structured learning provided. Our findings show that, although participants enjoyed using social media to support their MOOC experience and thought that they had benefitted from using it, some had objections.

The benefits included enhancing learning through the social and informal interaction with their peers, and from the online communities that formed around the CD MOOC. Connecting with peers using social media also strengthened participants' sense of belonging to the CD MOOC cohort.

Non-institutionally provided digital environments bring both opportunities and challenges to digital learning. Amongst the opportunities is the ability for online students to learn anywhere, on an array of devices, on multiple online platforms, and in their own time, allowing for personal flexibility and choice. The challenges of online learning include becoming skillful in and comfortable with new technology, developing ways to relate to and communicate with other learners online, and becoming comfortable about having an online presence and digital identity.

Most notable was the wide variety of differing views and experiences by the CD MOOC participants. The CD MOOC participants held contrasting views that highlighted how individual preferences for online learning differ considerably within the same learning cohort. This also highlighted the willingness and benefits for those who did venture outside the structured and provided learning environment.

\section{Recommendations}

When designing for MOOCs or online learning, participants' preferences for social media use should be taken into account. The design of content and delivery methods 
for the intended target audience should consider the cohort's demographics and background, and use MOOCs-centred research. Such predictors can help in the selection of platforms that are the most appropriate, based on the demographic data of social media usage, for example. Social media platforms such as Facebook and Twitter should be viewed by MOOC designers as an addition to a LMS rather than a substitution. Social media should ideally serve complementary purposes to a LMS, ensuring that material is not duplicated. Participants should be clearly informed that information communicated on social media does not duplicate anything else already given within the course/official platform, in order to persuade students that social media is not a waste of time.

Nevertheless, online designers need to ensure that learners are not given too many social media options, as more is not always better. Instead, more options may lead to confusion, intimidation, and learners who log off altogether. Our study demonstrated that CD MOOC participants found too many options of engagement and different online platforms overwhelming. They stated they were often unable to keep up to date with every post or discussion thread due to time restraints, and they worried about falling behind. As MOOC participants have busy lives and jobs, and often embark on a MOOC in their spare time, MOOCs should be simplified wherever possible. For this reason, the social media options should be limited in order to avoid information overload and minimise confusion for learners. It may be worth, for example, incorporating a Twitter feed directly into the LMS site, thereby opening access up to all participants and avoiding the requirement of logging into yet another social media site.

Several participants cited a lack of time for not engaging with social media in the CD MOOC, while others did not believe that social media contributed any value to their MOOC experience at all. As a result, it may be useful to outline in detail to students the contributions that social learning can bring to a MOOC and, indeed, to any online learning environment. Those who believe that conversations on social media are a waste of time may view things differently if they understand how conversations and knowledge sharing with their peers can support their learning experience.

Online learning should be designed around multiple learner preferences, if possible, to tailor the learning experience to each participant. Some learners prefer to separate their social and professional identities, while others are unconcerned about merging their social and professional lives, perhaps because they do not distinguish between the two. MOOC designers need to take this into account. One solution is to offer a few different platforms, in addition to the LMS, but not require that learners use them if they feel uncomfortable. Alternatively, ask learners to create professional identities on social media for all formal learning and professional development uses.

We have shown that despite the objections cited by participants, social media can be a powerful tool deployed in MOOCs and other digital learning: It can boost collaboration, enhance networking efforts, and improve learning experiences and outcomes.

\section{Ethics}

This project was approved for human research ethics by Swinburne's Human Research Ethics Committee (SUHREC) and follows the Australian Government's National Statement on Ethical Conduct in Human Research (2007). The data used in this study was de-identified prior to researchers accessing the primary data to ensure 


\section{G. Salmon et al.}

confidential treatment of participants' data. Conflicts of interest were minimal and resolved by employing researchers who were not involved in the deployment of the CD MOOC.

\section{Acknowledgements}

The authors thank Lee Partridge and Sid Nair of the University of Western Australia for their valuable comments on earlier versions of this paper.

\section{References}

Aghili, M., et al., (2014) 'Unifying informal and formal learning environments: educational use of social network sites through implementing community of inquiry framework', International Journal of e-Education, e-Business, e-Management and e-Learning, vol. 4, no. 3, pp. 191-196. doi: http://dx.doi.org/10.7763/IJEEEE.2014.V4.329

Balakrishnan, V. (2013) 'Using social networks to enhance teaching and learning experiences in higher learning institutions', Innovations in Education and Teaching International, vol. 51, no. 6, pp. 595-606. doi: http://dx.doi.org/10.1080/14703297.2013.863735

Bazeley, P. (2012) 'Integrative analysis strategies for mixed data sources', American Behavioral Scientist, vol. 56, no. 6, pp. 814-828.

Blaschke, L. M. (2014) 'Using social media to engage and develop the online learner in selfdetermined learning', Research in Learning Technology, vol. 22, 21635, doi: http://dx.doi. org/10.3402/rlt.v22.21635

Bosch, T. E. (2009) 'Using online social networking for teaching and learning: Facebook use at the University of Cape Town', Communication: South African Journal for Communication Theory and Research, vol. 35, no. 2, pp. 185-200. doi: http://dx.doi.org/10.1080/ 02500160903250648

Brownell, J. E. \& Swaner, L. E. (2010) Five High-Impact Practices: Research on Learning Outcomes, Completion, and Quality, Association of American Colleges and Universities, Washington, DC.

Davies, C., et al., (2010) 'Research and development to support the next stage of the Harnessing Technology Strategy', The Learner and their Context. The Technology-Based Experiences of Learners as they Approach and Enter the World of Work. A report for Becta, University of Oxford, Oxford.

de Freitas, S. I., Morgan, J. \& Gibson, D. (2015) 'Will MOOCs transform learning and teaching in higher education? Engagement and course retention in online learning provision', British Journal of Educational Technology, vol. 46, no. 3, pp. 455-471. doi: http://dx.doi.org/10.1111/bjet.12268

DeWitt, D., et al., (2014) 'Interactions in online forums: a case study among first year undergraduate students', Frontiers in Education (FE), vol. 2, no. 1, pp. 6-13.

Dodge, L. \& Kendall, M. E. (2004) 'Learning communities', College Teaching, vol. 52, no. 4 , pp. 150-155. doi: http://dx.doi.org/10.3200/CTCH.52.4.150-155

Ellison, N. B., Steinfield, C. \& Lampe, C. (2007) 'The benefits of Facebook "friends": social capital and college students' use of online social network sites', Journal of ComputerMediated Communication, vol. 12, no. 4, pp. 1143-1168. doi: http://dx.doi.org/10.1111/j. 1083-6101.2007.00367.x

Gray, K., Annabell, L. \& Kennedy, G. (2010) 'Medical students' use of Facebook to support learning: insights from four case studies', Medical Teacher, vol. 32, no. 12, pp. 971-976. doi: http://dx.doi.org/10.3109/0142159X.2010.497826

Henderson, M. (2015) 'The (mis) use of community of practice: delusion, confusion, and instrumentalism in educational technology research', in Critical Perspectives on Technology and Education, eds. S. Bulfin, N. F. Johnson \& C. Bigum, Palgrave Macmillan, New York, NY, pp. 127-140.

Henderson, M., Selwyn, N. \& Aston, R. (2015) 'What works and why? Student perceptions of "useful" digital technology in university teaching and learning', Studies in Higher Education, pp. 1-13. doi: http://dx.doi.org/10.1080/03075079.2015.1007946 
Hrastinski, S. \& Aghaee, N. M. (2012) 'How are campus students using social media to support their studies? An explorative interview study', Education and Information Technologies, vol. 17, no. 4, pp. 451-464.

Jones, N., et al., (2010) 'Get out of MySpace!', Computers in Education, vol. 54, no. 3, pp. 776-782.

Junco, R., Heiberger, G. \& Loken, E. (2010) 'The effect of Twitter on college student engagement and grades', Journal of Computer Assisted Learning, vol. 27, no. 2, pp. 119-132. doi: http://dx.doi.org/10.1111/j.1365-2729.2010.00387.x

Kaeomanee, Y., Rias, B. M. \& Perveen, R. (2012) 'Social software enhanced e-learning system to support knowledge sharing among students: Malaysian higher education institutions perspectives', Paper Presented at the 2012 International Conference of Computer \& Information Science (ICCIS), Kuala Lumpur.

Kassens-Noor, E. (2012) 'Twitter as a teaching practice to enhance active and informal learning in higher education: the case of sustainable tweets', Active Learning in Higher Education, vol. 13, no. 1, pp. 9-21. doi: http://dx.doi.org/10.1177/1469787411429190

Kim, H. N. (2008) 'The phenomenon of blogs and theoretical model of blog use in educational contexts', Computers \& Education, vol. 51, no. 3, pp. 1342-1352. doi: http://dx.doi.org/10. 1016/j.compedu.2007.12.005

Knox, J. (2014) 'Digital culture clash: "Massive" education in the e-learning and digital cultures MOOC', Distance Education, vol. 35, no. 2, pp. 164-177. doi: http://dx.doi.org/10. 1080/01587919.2014.917704

Kop, R., Fournier, H. \& Mak, J. S. F. (2011) 'A pedagogy of abundance or a pedagogy to support human beings? Participant support on massive open online courses', International Review of Research in Open and Distance Learning, vol. 12, pp. 74-93.

Lai, K.-W. (2015) 'Knowledge construction in online learning communities: a case study of a doctoral course', Studies in Higher Education, vol. 40, no. 4, pp. 561-579. doi: http://dx. doi.org/10.1080/03075079.2013.831402

Laird, T. (2014) Using Social Media in Education for Classroom Teaching, Student Learning, and Educator Professional Development, Queen's University, Kingston, Ontario, Canada.

Land, R. \& Bayne, S. (2008) 'Social technologies in higher education: authorship, subjectivity and temporality', Paper Presented at the Sixth International Conference on Networked Learning, Halkidiki, Greece.

Levinson, M. (2013) Where MOOCs Miss the Mark: The Student-Teacher Relationship [Web Log Post], Available at: http://www.edutopia.org/blog/where-MOOCs-miss-the-markmatt-levinson

Llorens, F. \& Capdeferro, N. (2011) 'Facebook's potential for collaborative e-learning', Revista de Universidad y Sociedad del Conocimiento (RUSC), vol. 8, no. 2, pp. 197-210. doi: http:// dx.doi.org/10.7238/rusc.v8i2.963

Madge, C., et al., (2009) 'Facebook, social integration and informal learning at university: "it is more for socialising and talking to friends about work than for actually doing work", Learning, Media and Technology, vol. 34, no. 2, pp. 141-155. doi: http://dx.doi.org/10.1080/ 17439880902923606

Maloney, E. J. (2007) 'What Web 2.0 can teach us about learning', The Chronicle of Higher Education, vol. 53, no. 18, p. B26.

Oblinger, D. \& Oblinger, J. (2005) 'Is it age or IT: first steps toward understanding the Net Generation', Educating the Net Generation, vol. 2, no. 1-2, p. 20.

Oliver, R., et al., (2007) 'Representing authentic learning designs supporting the development of online communities of learners', Journal of Learning Design, vol. 2, no. 2, pp. 1-21.

Özmen, B. \& Atici, B. (2014) 'The effects of social networking sites in distance learning on learners' academic achievements', European Journal of Open, Distance and E-Learning, vol. 17, no. 2, pp. 61-75. doi: http://dx.doi.org/10.2478/eurodl-2014-0019

Salmon, G. (2013) E-tivities: The Key to Active Online Learning, 2nd edn, Routledge, New York.

Salmon, G. (2015) Carpe Diem Learning Design: Preparation \& Workshop, Available at: http:// www.gillysalmon.com/carpe-diem.html

Salmon, G., et al., (2015) 'Experiential online development for educators: the example of the Carpe Diem MOOC', British Journal of Educational Technology, vol. 46, no. 3, pp. 542-556. doi: http://dx.doi.org/10.1111/bjet.12256

Salmon, G. \& Wright, P. (2014) 'Transforming future teaching through "Carpe Diem” learning design', Education Sciences, vol. 4, no. 1, pp. 52-63. 


\section{G. Salmon et al.}

Selwyn, N. (2009) 'Faceworking: exploring students' education-related use of Facebook', Learning, Media and Technology, vol. 34, no. 2, pp. 157-174. doi: http://dx.doi.org/10.1080/ 17439880902923622

Strauss, A. \& Corbin, J. (1998) Basics of qualitative research: techniques and procedures for developing grounded theory, 2nd edn, SAGE Publications, Inc., Thousand Oaks.

Sullivan, P. (2002) 'It's easier to be yourself when you are invisible: female college students discuss their online classroom experiences', Innovative Higher Education, vol. 27, no. 2, pp. 129-144. doi: http://dx.doi.org/10.1023/A:1021109410893

Tess, P. A. (2013) 'The role of social media in higher education classes (real and virtual) - a literature review', Computers in Human Behavior, vol. 29, no. 5, pp. A60-A68. doi: http:// dx.doi.org/10.1016/j.chb.2012.12.032

Thompson, L. \& Ku, H. Y. (2005) 'Chinese graduate students' experiences and attitudes toward online learning', Educational Media International, vol. 42, no. 1, pp. 33-47. doi: http://dx.doi.org/10.1080/09523980500116878

Veletsianos, G. \& Navarrete, C. (2012) 'Online social networks as formal learning environments: learner experiences and activities', The International Review of Research in Open and Distance Learning, vol. 13, no. 1, pp. 144-166.

Wodzicki, K., Schwämmlein, E. \& Moskaliuk, J. (2012) “"Actually, I wanted to learn”: studyrelated knowledge exchange on social networking sites', The Internet and Higher Education, vol. 15, no. 1, pp. 9-14. doi: http://dx.doi.org/10.1016/j.iheduc.2011.05.008

Yang, D., et al., (2013) 'Turn on, tune in, drop out: anticipating student dropouts in massive open online courses', Paper Presented at the 2013 NIPS Data-Driven Education Workshop, Lake Tahoe, NV.

Yu, A. Y., et al., (2010) 'Can learning be virtually boosted? An investigation of online social networking impacts', Computers \& Education, vol. 55, no. 4, pp. 1494-1503. doi: http://dx. doi.org/10.1016/j.compedu.2010.06.015

Yuan, J. \& Kim, C. (2014) 'Guidelines for facilitating the development of learning communities in online courses', Journal of Computer Assisted Learning, vol. 30, no. 3, pp. 220-232. doi: http://dx.doi.org/10.1111/jcal.12042

Ziegler, S. G. (2007) 'The (mis)education of Generation M', Learning, Media and Technology, vol. 32, no. 1, pp. 69-81. doi: http://dx.doi.org/10.1080/17439880601141302 